\title{
MORFOLOGÍA EN LA UMBRÍA DE LA SIERRA DE BERNIA
}

\author{
A. Morales Gil, C. Bru Ronda y M. Box Amorós
}

El área de estudio que se analiza a continuación se ubica en el complejo anticlinal de la Sierra de Bernia, el cual queda localizado a $10 \mathrm{Km}$ al SW del municipio de Benisa en un tramo del litoral alicantino perteneciente a las Béticas, y dentro de ellas, al sector geológicamente definido como Prebético meridional.

El objetivo de este trabajo se inserta en el concepto de la geomorfología climática y, concretamente, en los fenómenos del modelado que comporta el sistema periglacial, en el cual distinguiremos las actuaciones de este periglaciarismo en épocas cuaternarias pasadas, de la posible existencia de una dinámica periglacial actual en este ámbito.

Respecto a la presencia y permanencia de este tipo de morfología, TRICART ${ }^{1}$ indica que ha tenido y mantiene un desarrollo espacial muy amplio, no quedando solamente relegado a las altas latitudes, sino que se manifiesta igualmente en las altas altitudes, e incluso, en zonas templadas y en orografías cercanas al Mediterráneo, como es el caso que nos ocupa dentro de las Béticas.

La morfogénesis periglacial que vamos a estudiar ha necesitado de la interacción de diversos factores tanto físicos como biológicos para conformarse, a diferencia del fenómeno glacial, que es sustancialmente climático. En esta interacción encontramos: factores estructurales (litología, estructura y topografía), factores climáticos (altitud y orientación [118], temperatura, humedad y exposición), y por último, factores biológicos como poblamientos vegetales, ganado trashumante y la acción antrópica, que acentúa o modifica al conjunto final. La actuación de estos distintos elementos origina diversas formas periglaciares, entre las cuales hemos localizado en este sector los modelados sobre vertientes, destacando, los canchales de gravedad gelifractos o derrubios ordenados y lóbulos de gelifluxión. Su ubicación responde, pues, a una serie de premisas que, en el caso de los derrubios ordenados, se deben a una necesidad muy concreta de localización en base a la interacción de estos elementos ya que, preferentemente, se encuentran rellenando concavidades al pie de las cornisas cuya litología es friable y apta para estos procesos de gelifracción.

Dentro de estas premisas que han sido expuestas en otros estudios ${ }^{2}$, cabe destacar la necesidad de una importante cornisa rocosa que presente una litología masiva y friable; una concavidad al pie de esta cornisa que presente una base lo suficientemente ancha para que se desarrollen los taludes y con una cierta inclinación $\left(30^{\circ}-35^{\circ}\right)$; la influencia de una climatología propicia con la presencia de continuos ciclos hielo-deshielo $\mathrm{y}$, por último, una orientación $(\mathrm{N})$ al resguardo de los rayos solares.

${ }^{1}$ TRICART, J.: Traité de Geomorphologie. T. II: Le modelé des regions periglaciaires. Edit. SEDES. París, 1967.

${ }^{2}$ MORALES GIL, A. et alter: Formas periglaciares en las Cañadas del Teide (Tenerife). Edit. Aula de Cultura del Cabildo Insular de Tenerife. Santa Cruz de Tenerife, 1977.

ROSSELLÓ VERGER, V.M. y BERNABÉ MAESTRE, J.M.: «La montaña y sus valles: un dominio subhúmedo» en LÓPEZ GÓMEZ, A. y ROSSELLÓ VERGER, V.M.: Geografia de la provincia de Alicante. Excma. Diputación Provincial de Alicante. Alicante, 1978 p. 104.

GÓMEZ ORTIZ, A.: Síntesis geomorfológica del alto valle del Segre. Dpto. de Geografía. Univ. de Barcelona, 1981 p. 34. 
En relación a este planteamiento, la zona que se describe seguidamente presenta unas características bastante apropiadas para la formación de estos canchales gelifractos, si bien hay que analizar toda una serie de factores paralelos y coincidentes que nos pueden confirmar o, por lo menos, ayudar a discernir el valor morfológico que hoy en día suponen los mecanismos de hielo-deshielo en el suelo.

Es ésta una óptica integradora de todos los factores que inciden en la morfología del paisaje de este ámbito del Mediterráneo. Por ello, metodológicamente, se ha realizado un estudio de los aspectos geológicos, estructurales y litológicos de las unidades de relieve, analizando, a continuación, el clima que incide sobre este sector, y la biogeografía del medio. Por último, se interpreta la morfología resultante para lo cual se han realizado una serie de muestreos y su interpretación con el diagrama [119] de POSER y análisis de laboratorio que van a verificarnos la procedencia de estas formas.

\section{ASPECTOS GEOLÓGICOS, LITOLÓGICOS Y ESTRUCTURALES}

Elárea estudiada se enmarca en el contexto del Prebético meridional alicantino, en el que se incluye la serranía de Bernia. Ésta constituye una alineación montañosa enclavada en la comarca de la Marina y que, con una orientación NW-SE, desciende suavemente desde el N de Callosa d'Ensarriá hasta el Mediterráneo, en el Moro del Toix, donde separa, a través de ese contrafuerte, dos arcos concéntricos estructurales abiertos al mar en las costas de Calpe y Altea que albergan ambos sinclinales de sedimentación miocena. Dan estos sinclinales un paisaje modelado sobre suaves lomas disecadas por la acción de las aguas de arroyada, realizando el cierre semicircular, unos relieves montañosos que no sobrepasan la altitud de la Sierra de Bernia, por ello, se entiende que dicha serranía resalte en todo este sector en el que se desarrollan los amplios sinclinales.

A lo largo de sus casi $12 \mathrm{Km}$ de longitud, la afilada crestería de Bernia mantiene un rumbo constante, contrastando la sencillez de su forma en el paisaje con la complejidad geológica que muestra en los planes generales. Se trata de un anticlinal de base oligocena-aquitaniense que soporta una estructura cretáceo-eocena deslizada. Elnúcleo anticlinal puede verse muy bien a lo largo del Barranco del Mascarat, que aprovecha una falla, cortando la estructura de $\mathrm{N}$ a S, entre la Sierra del Toix y la pedriza de Bernia, aquí las calizas pierden la estratificación y pasan a ser una masa compacta triturada. A ambos lados de dicho barranco, al $\mathrm{N}$ y al $\mathrm{S}$, las capas vuelven a tener estratificación y buzan $60^{\circ}$ y $80^{\circ}$.

En la prolongación de la Sierra hacia el W, el anticlinal cierra violentamente en el término de Callosa d'Ensarriá en una especie de cierre periclinal y realiza el ensamblaje con la Sierra del Ferrer, quedando la prolongación W de sus capas, cortada por la falla de Bolulla.

La dirección NW-SE que mantiene constantemente el anticlinal oligoceno es anómala en la tectónica regional, con la presencia de fallas dextrógiras ${ }^{3}$, al igual que es curioso observar el hecho que se da en la cornisa de esta sierra donde está el Pico de Bernia $(1.128 \mathrm{~m})$, que ofrece un magnífico ejemplo de un paquete de calizas lutecienses, descansando [120] limpiamente sobre la charnela anticlinal del Oligoceno-Aquitaniense. Con ello, la crestería del E y del centro es sustituida por una eocena en la parte occidental. En el plano general, se aprecia bien la inflexión hacia el S de las capas desplazadas oligocenas para dejar paso al Eoceno. Complicando más las cosas, el aspecto exterior de ambas calizas es el mismo y la sierra desde lejos da la sensación de ser una crestería homogénea y continua.

Subiendo por la carretera que va de Benisa a Bernia, se puede ver hundirse, casi

${ }^{3}$ RODRÍGUEZ ESTRELLA, T.: Geología e hidrología del sector Alcaraz-Lietor-Yeste (Prov. de Albacete). Sintesis geológica de la zona Prebética. I.G.M.E. Madrid, 1979 p. 217. 
verticales, y con una inflexión violenta, las capas del Oligoceno que son, lateralmente, remontadas por las calizas eocenas. Este hecho da idea de las tensiones tectónicas y de las presiones que han sufrido los distintos paquetes estratigráficos, hecho éste que se refleja en las múltiples fallas que cruzan Bernia de $\mathrm{N}$ a $\mathrm{S}$ y que son fallas de desagarre (Bolulla y Mascarat, entre otras), así como también se puede observar la profusión de diaclasas que afectan a los estratos.

Adosado a Bernia, encontramos otro anticlinal que conviene analizar, el cual queda constituido por la Solana, Tosal Navarro (o Loma Larga) y Tosal Gros, formando un conjunto monoclinal que no es más que un espolón de la Sierra de Bernia que arranca del flanco N perpendicular a ella, en el sector de la pedriza y lo hace dividiendo a esta sierra en dos sectores W-E. Las capas del anticlinal, con dirección SE-NE, se curvan abriéndose en abanico para adaptarse por el sur a la dirección de la Sierra de Bernia que es ESE, hecho éste de gran trascendencia por la violencia del encuentro en las direcciones opuestas.

La importancia del contacto entre estas dos estructuras anticlinales radica en la delimitación del dominio analizado, ya que a partir del encuentro con este espolón se desarrolla el sector de máximas altitudes que culmina hacia el $\mathrm{W}$ en el Pico de Bernia (1.128 $\mathrm{m}$ ) y va a ser en este sector, que se desarrolla al pie de la cornisa, donde se encuentran los primeros restos de morfogénesis periglacial.

Litología.- Estas unidades estructurales del Prebético meridional alicantino presentan, básicamente, dos tipos de materiales; en la base de los anticlinales aparecen margas oligocenas de color salmón y conglomerados, arcillas y calizas organógenas con Lepidocyclinas y margas y margocalizas tipo Flysch con foraminíferos; en las cumbres, sobre las que desarrolla el modelado periglacial, se encuentra el Oligoceno de los tramos superiores compuesto por calizas masivas, en ocasiones brechoides y que alcanzan en este sector de la Sierra de Bernia su máxima potencia. El Eoceno que remonta el área $\mathrm{N}$ de la charnela de Bernia, y que constituye el principal material del que se nutren los canchales, está compuesto de un paquete de calizas organógenas con Nunmulites que tiene una potencia considerable. Este tipo de rocas calcáreas sedimentarias [121] de origen orgánico son calizas de acumulación, constituidas por la cementación de caparazones de animales muertos, alcanzando estas calizas nunmulíticas con foraminíferos una gran extensión a principios del Terciario, en el Paleógeno, originadas en los mares cálidos a poca profundidad y sobre fondos planos, formándose en períodos largos dilatados y carentes o muy pobres en sedimentación detrítica. Estas rocas calcáreas contienen por lo menos un $50 \%$ de carbonato cálcico, con una dureza 3, dan efervescencia en frío con los ácidos y, aunque son muy poco solubles en agua pura, son solubles en agua cargada de gas carbónico (hasta $2 \mathrm{mg} / \mathrm{l}$ ) debido a la formación de bicarbonato cálcico.

Estas calizas biohérmicas de grano medio a grueso y disyunción regular aparecen netamente estratificadas en bancos de potencia variables entre 0,50 y $0,80 \mathrm{~m}$ con una franca orientación sinsedimentaria de sus elementos biogénicos que simulan una falsa esquistosidad. La componente principal es la caliza, con cantidades menos importantes de dolomías y aragonito, y pequeñas porciones de calcedonia, cuarzo y silicato.

La abundancia y distribución de los fósiles que alberga esta roca es causa determinante de su estructura, que es bastante porosa, por lo que está sometida a reacciones químicas, sobre todo durante el proceso de diagénesis, con una absorción durante este proceso del magnesio disuelto en el agua del mar (dolomitización del aragonito y, en menor medida, de la caliza). Debido a esto, presenta una profusión de drusas y cavidades tapizadas de cristales y rellenas de arcilla residual. Frecuentes son también las estructuras de separación (brechas intraformacionales) y formas de disolución química con redeposición de la fracción insoluble (especialmente arcillas y óxidos de hierro). Las reacciones químicas han dado lugar, en todo el sector, a precipitados de carbonato cálcico presentes en las formaciones de calcita en las que se 
encuentran los pianos de exfoliación romboédrica típica. Esta precipitación del carbonato cálcico se produce cuando al provocarse la extrusión $\mathrm{CO}_{2}$ o de $\mathrm{H}_{2} \mathrm{O}$ líquida destruye el equilibrio en favor del primer miembro y se da el precipitado (BELLAIR-POMEROL, 1974). Así, cuando se origina una pérdida de $\mathrm{H}_{2} \mathrm{O}$ y se da una concentración por el hielo, acontece la formación de calcita que puede cementar las gravas de los aluviones, como ocurrió durante los períodos fríos del Cuaternario en el sector, formando una amalgama de cantos consolidados.

Esta litología terciaria, susceptible a los fenómenos kársticos y periglaciales, presenta unas estructuras que se resuelven en estilos imbricados y cabalgaduras que nos sugieren una gran intensidad en los plegamientos y de la tectónica que afectó a este sector, hecho que influirá decisivamente en el diaclasamiento de las rocas a través de líneas de debilidad [122] estructural y en los contactos litológicos de diferente resistencia. Estas acciones inciden en la cohesión de la roca, en definitiva, en las especiales condiciones morfolitológicas que favorecen la actuación crioclástica.

Tectónica.- En este sentido, podríamos hablar de la evolución del sector y su complicada tectogénesis. Durante la etapa preorogénica y a partir del Lías medio superior, tuvo lugar en el zócalo un hundimiento de bloques que dio lugar a unos cambios en la sedimentación. Fue entonces cuando se diferenciaron la zona Prebética y la Subbética, e incluso, los distintos dominios dentro de éstas. Ligado a esas fallas de zócalo, se produjeron en la cobertura unas áreas de flexura que marcaron los límites entre facies y potencias de las series. Estas áreas ya constituyeron, desde la etapa preorogénica, puntos débiles e inestables en los que el Trias pudo actuar preferentemente, dando lugar a zonas levantadas, umbrales o, incluso, franjas diapíricas embrionarias.

Al sobrevenir la etapa orogénica, estas áreas inestables de flexura y de cambios estratigráficos importantes fueron las más vulnerables a fracturarse y desplazarse hacia el $\mathrm{N}$, de ahí que se asienten en ellas los cabalgamientos importantes (Eoceno superpuesto al Oligoceno, como en el Klipper de Ifach, Serranía de Bernia y Sierra de Oltá) desplazamientos hacia el N, a veces, de 15 y $30 \mathrm{Kms}$ coincidiendo estos cabalgamientos con la separación de distintos dominios paleogeográficos ${ }^{4}$. Las primeras fases de plegamiento para el sector comienzan a darse entre el Eoceno y el Oligoceno, produciéndose en este último la fractura de las capas más profundas que actúan de forma rígida. No obstante, durante la fase tectónica neoalpina (entre el Burdigaliense superior-Langhiense inferior) se dio una tectónica más intensa que la anterior y a ella se debe el plegamiento de la serie terciaria y la reforma de las estructuras plegadas mesozoicas y eocenas. Afectará esta tectónica al flanco N de la Sierra de Bernia y, sobre todo, a la cuenca miocena de Calpe.

La importancia de estos movimientos entre el Oligoceno y el Mioceno inferior se caracteriza por dos movimientos isostáticos de signo contrario: -hundimiento de la cuenca miocena del Calpe al $\mathrm{N}$ de Bernia, y -levantamiento del diapiro triásico de Altea, situado al SE de Bernia. La banda de separación entre estas dos zonas sigue el eje actual del anticlinal, y se encuentra entre las áreas isostáticas de signo contrario, siendo la línea preferente para el progreso del diapiro hacia el W. Esta banda de separación que constituye Bernia se arruga y deforma por la salida del Trias formándose el anticlinal actual oligo-mioceno de la Sierra de Bernia. Todo el conjunto se fractura con fallas verticales que parten del [123] núcleo central del diapiro que progresan, centrífugamente, durante todo el Mioceno medio, quedando dislocados y levantados en el área central del mismo una serie de bloques o témpanos que abarcan desde el Eoceno al Trias, los cuales se deslizan hacia el N y NE. Los deslizamientos, indudablemente de tipo gravitacional, son diferenciales y de mayor intensidad en las capas plásticas que van funcionando como superficies de despegue, siendo las series sedimentarias más altas y potentes las que

\footnotetext{
${ }^{4}$ RODRÍGUEZ ESTRELLA, T. Op. cit. pp. 255-56.
} 
alcanzan deslizamientos más extensos hacia el NE. Así, el Eoceno sobre su base de Eoceno inferior plástico la rebasa en algunos puntos, siendo testigos de este hecho la Sierra de Oltá, la estratigrafía corrida sobre la Sierra de Bernia, en el NW y también el klipper de Ifach.

En toda esta evolución tectónica, no hay que abandonar la idea de que esta eclosión diapírica está íntimamente ligada a las fallas de zócalo a las que se ha aludido y que se revitalizan en esta etapa tectónica.

Por último, una fase de plegamiento o tectónica de reajuste, caracterizada para la región valenciana por MONTENAT y a la que atribuye una edad postpliocena y postvillafranquiense, dará lugar a estructuras con pliegues y fallas inversas ${ }^{5}$.

De todas estas fases de plegamiento que hemos analizado se desprende la importancia que tuvieron aquí estas fases tectónicas y que hacen que se incluya este sector, al igual que otros pertenecientes al Prebético, como uno de los más tectonizados de la Península, sin olvidar, por último, que durante todo el Cuaternario prosiguen estas pulsaciones aunque muy atenuadas.

De la intensidad y complejidad de la tectónica que afectó a esta zona, se entiende que entre los factores que contribuyen a la disgregación de las rocas, el diaclasamiento sea, para este caso, un hecho primordial y más cuando es el hielo el que actúa en esa disgregación como agente principal. El hielo va a rellenar los intersticios vacíos entre esas microformas frecuentes en las calizas y que estallan ante la presión considerable que ejerce el agua al helarse, provocando la gelifracción. El fenómeno de diaclasamiento y, en relación a lo antes mencionado, se vincula a los hechos acaecidos durante el Mioceno inferior-medio, principalmente.

Los movimientos tangenciales dieron lugar a la formación de los relieves y a unas fracturas verticales. Posteriormente a estos movimientos tangenciales, en los que domina claramente un estado de comprensión general, estos esfuerzos ceden en su empeño y tiene lugar una fase de reajuste de bloques, es decir, viene un estado de descompresión o distensión [124] que origina gran cantidad de fallas y diaclasas normales a las anteriores, que afectan, sobre todo, a los materiales rígidos ${ }^{6}$. Estas diaclasas producidas por el relajamiento de la presión tras los esfuerzos tectónicos se deben a un proceso de descarga y son, en muchos casos, virtuales, como si fueran vetas en las rocas y únicamente se descubren cuando entra en juego el proceso de disgregación formando entonces grietas que se pueden agrandar y que dividen a la roca en fragmentos.

La acción disgregadora del hielo ante esta roca desnuda y diaclasada es muy activa, sobre todo en la cornisa de la que se nutre el talud, donde en base a la verticalidad impide la existencia de un tapiz vegetal que la recubra y resguarde de esta acción directa. Sin embargo, en oposición a esto último, al pie de la cornisa donde las verticalidades se reducen un poco, las diaclasas son ocupadas por ciertos organismos que actúan mecánicamente sobre el relieve, en especial las plantas que colonizan estas diaclasas y cuyas raíces ensanchan las grietas y dislocan los bloques, aunque este aspecto será analizado posteriormente.

\section{CONDICIONAMIENTOS CLIMÁTICOS}

A la hora de analizar las condiciones climáticas en la zona donde se ha desarrollado el trabajo se presentó en primera instancia un problema, sin lugar a dudas, importante: la inexistencia de un observatorio meteorológico con cuyos datos poder poner de manifiesto de la

\footnotetext{
${ }^{5}$ MONTENAT, Ch.: «Pliocene Superieur et Villafranchien dans le Levant espagnol (Murcie-Alicante)» Boletín Geológico y Minero T. XXXII pp. 52-58.

${ }^{6}$ LERET, G. et alter: Memoria y hoja del Mapa Geológico de España E. 1:50.000 de Elda (no 817). I. G. M. E. pp. 52-53.
} 
manera más próxima a la realidad las situaciones climáticas imperantes en dicha área.

El observatorio más cercano es el de Benisa-convento, a unos $10 \mathrm{Km}$ en línea recta de la zona de canchales estudiada, del cual hemos extraído una parte de los datos pluviométricos y la totalidad de los registros térmicos. Lógicamente, la utilización de estos datos entrañaba el problema de la diferente altitud a la que se encuentran situados ambos puntos, de manera que para subsanar dicho inconveniente, sobre todo desde el punto de vista térmico, se hayan tenido que extrapolar las series con la utilización del gradiente de estado medio del que ha resultado una diferencia de $5,2^{\circ} \mathrm{C}$ entre ambas localizaciones. De todos modos, la simple referencia a unos datos más o menos trabajados no hubiera sido lo suficientemente clarificadora si no se hubiera podido contar con la valiosa información que el Padre Arbona, observador oficial de la estación Benisa-convento, recogió en sus registros diarios, anotando en sus libros no sólo lo que acontecía en dicho lugar sino también en sus [125] alrededores, de ahí que se hayan podido contabilizar los días de nieve en Bernia, factor de principal magnitud para la explicación de los fenómenos perigiaciales.

Planteamiento dinámico.- Elárea de estudio se encuentra inserta en el sector meridional de la zona templada, en el contacto con las altas presiones subtropicales.

El factor fundamental es la presencia del anticiclón de las Azores, célula de origen dinámico que oscila a lo largo del año con arreglo al mecanismo cósmico de las estaciones. En invierno queda acantonado por bajo de $\operatorname{los} 35^{\circ} \mathrm{L}$. N., mientras que en verano presenta una ganancia latitudinal llegando a los $40^{\circ}-45^{\circ}$ L.N. La presencia de este máximo depara, por su mecanismo de subsidencia, sequía y cielos despejados. Sin embargo, su trascendencia es de vital importancia no sólo por este hecho sino también porque en función de su posición actúa como elemento desviador de la trayectoria de los ciclones extratropicales que ven así dificultado su ingreso en el Mediterráneo.

Por otra parte, frente a este predominio estival de la cobertura anticiclónica, el resto del año la Península Ibérica se encuentra inmersa en la circulación general del W, y, lógicamente barrida por los individuos ciclónicos del frente polar que, sin embargo, poseen una escasa trascendencia pluviométrica en el área del SE peninsular por su situación de sotavento respecto a dicho flujo. Únicamente, estos ciclones noruegos pueden ser responsables de precipitaciones cuando después de su penetración en el Mediterráneo son revitalizados por el contacto con esta superficie marina cálida.

Aparte de estos hechos claros, cobertura del anticiclón de las Azores durante el verano y dominio de la circulación general del $\mathrm{W}$ en el resto del año, aparecen otra serie de situaciones que, por supuesto, no poseen un carácter permanente, pero cuya efectividad es manifiesta. Así, en cuanto a situaciones anticiclónicas se refiere, el máximo centroeuropeo, el ruso-siberiano o el finlandés, pueden proyectar sobre la Península aire extremadamente frío que haga bajar de manera considerable los registros térmicos. Tampoco los mínimos barométricos que inciden en el área poseen una categoría y permanencia suficiente, tan sólo cabe destacar la existencia de una zona depresionaria en el Mediterráneo occidental, resultado de la presencia de bajas presiones de origen vario.

Características climáticas de la comarca.- A la hora de encuadrar el área de estudio dentro de un contexto de climatología regional, se ha tenido en cuenta el índice de Thornthwaite cuyo balance hídrico ha permitido [126] la clasificación de la misma como C1B2'da', es decir, como un clima seco subhúmedo mesotérmico con pequeño exceso de agua y baja concentración 
de la eficacia térmica ${ }^{7}$; en base a este parámetro, CLAVERO PARICIO ${ }^{8}$ incluye este sector en la periferia de la fachada lluviosa del macizo de Alcoy, donde el ritmo estacional de las precipitaciones presenta una distribución otoño-invierno-primavera-verano, propio de la llanura litoral. El período seco es muy pronunciado, afectando además de a julio y agosto, en ocasiones, a junio o septiembre. La nieve es poco frecuente, oscilando entre 0,4 días en Callosa d'Ensarriá y el máximo de 2,9 en Agres.

Por supuesto, uno de los problemas que encuentra cualquier investigador de la climatología es la escasez de observatorios en altura; esta deficiencia le obliga a enmarcar toda una zona dentro de un mismo contexto climático, sin embargo, la altitud juega un papel fundamental, así como la exposición de cara a matizar unos factores u otros; por lo tanto, se ha de considerar que, en este caso, la Sierra de Bernia constituye un microclima en el que los registros obtenidos en Benisa aparecerán modificados por la impronta del relieve.

Análisis de temperaturas.- A la hora de analizar los registros térmicos, el primer problema planteado fue el de encontrar series continuas y completas que abarcaran un período de tiempo suficientemente amplio, de ahí que se haya tenido que trabajar para establecer el régimen térmico sólo con los datos del intervalo 1970-1981, recogidos en el mencionado observatorio de Benisa-convento. El estudio de esta serie ha dado como resultado la existencia de una temperatura media anual de $16,2^{\circ} \mathrm{C}$. El mínimo se registra en el mes de enero, alcanzándose las temperaturas máximas durante los meses de julio y agosto.

Sin lugar a dudas, es el registro de las temperaturas mínimas el que a efecto del estudio de los fenómenos periglaciales alcanza mayor importancia. Para realizar dicho análisis se ha efectuado un vaciado de los registros día por día en el período mencionado. Como ya se ha dicho, el inconveniente de la diferencia de altitud entre el observatorio utilizado ( $300 \mathrm{~m}$ sobre el nivel del mar) y la cornisa culminante de Bernia a cuyo pie se asientan los canchales (aprox. $1.100 \mathrm{~m}$ sobre el nivel del mar), se subsanó con la utilización del gradiente de estado medio de cuya aplicación han resultado los siguientes datos: [127]

$\underline{M E S}$

Enero

Febrero

Marzo

Abril

Octubre

Noviembre

Diciembre

\section{$\underline{N^{o} \text { medio de dias con } t=0^{\circ} \mathrm{C} / t<0^{\circ} \mathrm{C}}$}

4,0

1,6

0,1

1,4

2,6

De este cuadro se desprende que el período frío se extiende de noviembre a abril, siendo los meses de enero y febrero los que registran el mayor número de días con temperaturas de $0^{\circ} \mathrm{C}$

${ }^{7}$ BRU RONDA, C.: «El sinclinal de Benisa-Teulada. Estudio morfoestructural e hidrológico». Dicho artículo forma parte de esta revista.

${ }^{8}$ CLAVERO PARICIO, P.L.: Los climas de la región valenciana. Resumen de Tesis Doctoral. Barcelona, 1980 p. 63. 
o por bajo de dicho umbral, con un ligero predominio del mes de enero.

La temperatura media mínima alcanza un valor de $2,3^{\circ} \mathrm{C}$, siendo la temperatura mínima extrema la registrada el día 2 de enero de 1971 con $-7,7^{\circ} \mathrm{C}$. En líneas generales las situaciones que provocan registros iguales o inferiores a $0^{\circ} \mathrm{C}$ vienen determinadas por la afluencia de aire polar continental, vehiculado por isobaras cuya trayectoria envía desde el área centro-europea vientos de componente $\mathrm{NE}$ con un trazado prácticamente rectilíneo hasta las áreas levantinas. La invasión de este aire polar suele tener una duración de varios días, así, ese registro de $-7^{\prime} 7^{\circ} \mathrm{C}$ es el resultado de una ola de frío que comenzó a generarse en los últimos días de diciembre de 1970 con un potente anticiclón térmico ubicado al NW del archipiélago británico y extendido por toda Europa occidental, de manera que, por la disposición de sus isobaras, canalizaba hacia las tierras valencianas, a través del pasillo del Ródano, un flujo de aire extraordinariamente frío y que culminó en los días 2 y 3 de enero de 1971 con registros térmicos de $-7,7^{\circ} \mathrm{C}$ y $-6,8^{\circ} \mathrm{C}$ en Bernia, respectivamente.

Las precipitaciones.- Uno de los factores básicos de cara a la explicación de los fenómenos del modelado en la zona de estudio es la existencia de un elemento, el agua, cuya acción se manifiesta de múltiples formas: disolviendo la roca, es decir, originando procesos de karstificación, permitiendo la presencia de una vegetación que actúa química y mecánicamente, además de dar lugar a fenómenos de crioclástica cuando las temperaturas ambientales caen por bajo de $0^{\circ} \mathrm{C}$.

Para su estudio se han analizado los datos recogidos en dos observatorios, el de Benisa-convento y el de Pinos, dependiente del primero. Las series utilizadas, en el segundo de los observatorios mencionados, no son lo suficientemente amplias como para permitir una caracterización climática que se ajuste a las condiciones reales, pero de su comparación sí pueden extraerse una serie de consecuencias válidas. El hecho de que [128] se hayan utilizado series tan breves obedece a la razón de la inexistencia en dicho observatorio de registros más amplios temporalmente, aunque los mismos pueden dar una visión de conjunto, sobre todo, de cara a matizar las diferencias entre ambas ubicaciones.

El observatorio de Benisa-convento, como ya se ha dicho, se encuentra situado a unos $10 \mathrm{Km}$ del área de estudio, mientras que el de Pinos se haya ubicado al pie mismo de la Sierra de Bernia, en la vertiente donde aparecen los canchales analizados en el presente trabajo. Las diferencias entre uno y otro vienen a corroborar la idea, antes expuesta, del microclima que genera Bernia por su altitud y exposición.

Elperíodo utilizado para el observatorio de Benisa-convento ha sido de 1955-1979 y para el de Pinos de 1969-1977. En el primero, la precipitación media anual es de 543,9 mm, mientras que en el segundo alcanza los 636,3 mm. Dichos totales se reparten a lo largo del año de manera distinta en uno y otro, así en Benisa el ritmo estacional de las precipitaciones es otoño-invierno-primavera-verano, en el período estudiado y con muy escasa diferencia entre los registros de otoño e invierno; en el observatorio de Pinos, el ritmo estacional varía a primavera-invierno-otoño-verano. Este hecho puede tener una gran trascendencia para la explicación de los fenómenos periglaciares puesto que es, precisamente, en invierno cuando en Pinos se produce el $29,3 \%$ de la precipitación anual y la mayor parte de los registros térmicos por bajo de $0^{\circ} \mathrm{C}(58 \%)$.

Al igual que con el análisis térmico se ha efectuado un vaciado día por día de los totales pluviométricos, en ambos observatorios, haciendo especial hincapié en aquellos días donde la temperatura quedaba por bajo del umbral mencionado. De dicho estudio se puede extraer la conclusión de que entre ambas localizaciones existe una diferencia cuantitativa. En primer lugar, en el observatorio de Pinos son menos numerosos los días en que coinciden temperaturas por bajo de $0^{\circ} \mathrm{C}$ y precipitaciones (38,8\% y $42,8 \%$ en Benisa), y en segundo lugar, en los días en que ambos fenómenos son coincidentes en los dos observatorios utilizados, el de Pinos registra una 
mayor cuantía pluviométrica.

De ello se desprende el efecto orográfico que ejerce la Sierra de Bernia, máxime teniendo en cuenta que en los días en que se producen precipitaciones, el viento predominante es de componente NE o NW, direcciones que por la propia disposición de este murallón montañoso hacen que los flujos de aire cargados de humedad choquen contra él y en su ascenso experimenten un fenómeno de condensación suficientemente importante como para que se produzca en esta vertiente la descarga de precipitaciones.

A ello hay que añadir que, indudablemente, no todos los días en que [129] se registran temperaturas inferiores a $0^{\circ} \mathrm{C}$ se producen precipitaciones, pero es de destacar el hecho de que en una proporción importante, éstas han tenido lugar en días anteriores a dicho registro, lo que es un factor crucial de cara a la explicación de fenómenos geomórficos periglaciares. Así por ejemplo, entre los días 10-12-14-15-18 de Diciembre de 1975 cayeron en Pinos un total de 106,5 mm y desde el día 21 al 27 del mismo mes se registraron en Bernia temperaturas inferiores a $0^{\circ} \mathrm{C}$. Del estudio realizado se desprende que en Benisa, en el 57,1\% de los casos la precipitación se produjo en días anteriores al registro por bajo de $0^{\circ} \mathrm{C}$, mientras que en Pinos dicho porcentaje alcanza un valor del $61,1 \%$.

Por lo que se refiere a los días de nieve en Bernia, su contabilización ha sido posible, como ya dijimos, gracias a las anotaciones del padre Arbona en el observatorio de Benisa-convento, así, en el período analizado (1969-1981), de un total de 289 días con temperaturas inferiores o iguales a $0^{\circ} \mathrm{C}$ en Bernia, 6 han registrado precipitación en forma de nieve, lo que supone un porcentaje del 2,0\%.

Otro de los factores a tener en cuenta en la dinámica periglacial es el de la existencia de humedades relativas elevadas que oscilan entre el 64\% en el mes de Enero y el 68\% en el de Julio, cuantificadas para dicho sector por CLAVERO PARICIO ${ }^{9}$. La presencia de un aire cargado de considerable vapor de agua es muy importante si se tiene en cuenta el efecto de pared fría que posee la crestería de Bernia. Este efecto contribuye a transformar ese vapor de agua, en ocasiones, en escarcha cuya acción morfogenética coadyuvaría, aunque en menor medida, a la destrucción de la roca.

En el análisis de las precipitaciones no solamente se ha de tener en cuenta el total pluviométrico sino que se ha de contar, igualmente, con un factor de vital importancia por su condición de agente erosivo: la intensidad. Las lluvias en este sector, como en la casi totalidad del SE peninsular, poseen un carácter tormentoso y su génesis va ligada íntimamente con la formalización de procesos de gota fría, de manera que en ocasiones en un solo día puede caer un porcentaje muy importante del total anual. Así, por ejemplo, en el período 1955-1979 estudiado en la estación de Benisa-convento, el día 6 de Octubre de 1971 cayeron un total de $244,0 \mathrm{~mm}$, lo que supuso el $26,0 \%$ del total anual $(907,8 \mathrm{~mm})$. Indudablemente, la acción morfogenética de estas precipitaciones, producidas por una combinación de mecanismos (embolsamientos de aire frío en altura, exageración del gradiente térmico estático en la vertical, disposición de las cadenas montañosas litorales, [130] etc.) juega un papel muy importante en el desmantelamiento de las superficies rocosas.

\section{LOS PROCESOS DEL MODELADO}

Uno de los agentes elementales para explicar los fenómenos del modelado en la zona de estudio es la humedad que se manifiesta de múltiples maneras, contribuyendo todas ellas a un proceso de destrucción de las rocas. Entre estas formas destacan los procesos de karstificación,

${ }^{9}$ CLAVERO PARICIO, P.L.: «Influencia del Mediterráneo en las precipitaciones del País Valenciano» en Notes de Geografia fisica 1. Barcelona, 1979 pp. 15-16. 
la presencia de formaciones vegetales, los efectos de la arroyada, los mecanismos de condensación, etc.

La karstificación.- La forma más espectacular es, sin lugar a dudas, la existencia de precipitaciones. Existe de forma general y por encima del agua natural una atmósfera conteniendo gas carbónico. Este agua disuelve cierta cantidad de dicho gas ${ }^{10}$, existiendo una proporción en el contenido del mismo entre el agua y la atmósfera antes de la penetración en el suelo del agua de lluvia. La corrosión de las rocas calcáreas en la cornisa de Bernia se encuentra, en gran medida, favorecida por la tectonización de la misma.

Sin embargo, este ataque erosivo se ve incrementado por la presencia de factores bioquímicos, puesto que la existencia de un tapiz vegetal, tal y como el que aparece en este sector diaclasado de la cornisa de Bernia, es un elemento importante en la producción de gas carbónico. Además, en dicha cobertura, se pueden producir reacciones bioquímicas con formación de productos corrosivos, entre los que destacan los ácidos húmicos que disuelven la caliza. Igualmente, la descomposición de las materias orgánicas proporciona también ácidos que, como el acético, butírico y oxálico, se combinan con los húmicos para atacar la roca calcárea (RENAULT, Ph. 1971).

Estos procesos combinados originan un sistema erosivo cuya acción se manifiesta en la destrucción progresiva de la roca caliza, haciéndola susceptible de ser atacada por otros fenómenos geomórficos. El resultado de toda esta combinación de mecanismos es la aparición de un importante proceso de karstificación en el que juegan de manera primordial una serie de factores estructurales como son la litología, la tectónica y la estratigrafía.

Ya se ha dicho que, desde un punto de vista litológico, la cornisa de Bernia presenta una componente a base, fundamentalmente, de calizas relativamente puras $(50 \%$ de carbonato cálcico) que han sido depositadas [131] en bancos cuyo espesor es considerable $(0,50-0,80 \mathrm{~m})$ y a las que los efectos tectónicos han diaclasado, fracturado y desnivelado. Todo ello favorece los procesos de karstificación, apareciendo tanto formas externas o epigeas como internas, sibien son las primeras las que muestran un claro predominio a pesar de que la desnivelación o la existencia de accidentes tectónicos en el interior de la masa calcárea tienen la suficiente entidad, la composición litológica de la crestería no permite la aparición de una circulación kárstica hipogea importante. Como queda dicho, es la karstificación superficial la más abundante, desde los simples lapiaces, íntimamente ligados a las diaclasas y las dolinas, situadas preferentemente en el encuentro de planos de estratificación con diaclasas y fallas ${ }^{11}$. Una de estas dolinas localizadas presenta un aprovechamiento antrópico hoy abandonado, de manera que se encuentra aterrazada siguiendo las curvas de nivel. El sumidero de la dolina origina, en función de la intensa tectonización, una pequeña red hídrica hipogea cuyo estadio final es una resurgencia aprovechada como abrevadero para los ganados que pastan en el área.

La arroyada.- Existe otra forma de actuación del agua y que se relaciona, fundamentalmente, con la intensidad de las precipitaciones, así, ROSSELLÓ afirma que "sin llegar a la categoría de escorrentía fluvial y dejando aparte la función física de la alternancia humidificación/desecación, las lluvias o aguaceros torrenciales, sobre todo si son violentos, desempeñan un papel en el desprendimiento, transporte, acumulación y clasificación de los

${ }^{10}$ RENAULT, Ph.: La formación de las cavernas. Edit. Oikos-Tau (Colec. Qué sé?, no 60) Barcelona, 1971 p. 38.

${ }^{11}$ CORRA, G.: «Le rôle des facteurs structuraux dans la gènese et dans l'evolution des morphologies karstiques» en Revue de Geographie alpine, 1978 n 3 p. 263. 
derrubios de ladera» ${ }^{12}$. Como ya se ha dicho, por la situación climática del área dentro del contexto peninsular, una parte muy considerable de las precipitaciones se producen en las épocas equinocciales y ligadas, básicamente, a procesos de gota fría o baja desprendida en altura. La característica prioritaria de dichas precipitaciones es su fuerte intensidad horaria, de manera que en ocasiones en un solo día puede caer más de la mitad del total anual. Lógicamente, el efecto erosivo que estos chubascos torrenciales pueda tener sobre superficies más o menos disgregadas por otros factores es importante, contribuyendo al arrastre de materiales y a su deposición en las zonas de acumulación (canchales) aparte de posibilitar la movilidad de la masa pedregosa.

La acción de las plantas.- Un elemento íntimamente relacionado con la existencia de humedad es la presencia de formaciones vegetales. [132] Las comunidades que aparecen en la sierra de Bernia y, en general, en toda la comarca de la Marina pertenecen a las alianzas Rosmarino-Ericion y Oleo-Ceratonion. De la primera se han encontrado diversas especies en la crestería estudiada, destacando, entre otras, la Stipa juncea acomodada entre las diaclasas de las rocas donde ejerce una importante labor erosiva de disgregación, la Erica multiflora que es dentro de las ericáceas, la especie más adaptada a unas condiciones calcófilas, el romero Rosmarinus officinalis, el espliego, lavándula, etc.

Igualmente, el palmito Chamaerops humilis, la única palmera que de forma autóctona se presenta en el continente europe ${ }^{13}$ perteneciente a la alianza Oleo-Ceratonion, aparece en la crestería de Bernia a una altitud de $800 \mathrm{~m}$. Se trata de una especie acomodaticia de condiciones calcáreas que son las que se dan en el área de estudio, si bien, únicamente, se han encontrado aquí dos o tres ejemplares, aunque conviene hacer la salvedad de que en áreas próximas, en la misma sierra de Bernia, con unas condiciones climáticas más templadas, el palmito o margalló es mucho más abundante y ello está en función de las limitaciones altitudinales de esta especie, de manera que en la vertiente de solana se puede encontrar a altitudes similares mientras que en la umbría su presencia se ve mucho más restringida.

La vegetación juega en un doble sentido puesto que, en ocasiones, actúa como un agente erosivo mientras que en otros lo hace como elemento de fijación de los materiales. Así, la vegetación en la cornisa de Bernia ejerce un papel destructor por cuanto que para poder desarrollarse se enclava entre las diaclasas de la caliza y ello por dos motivos, en primer lugar, porque es aquí donde en función de los procesos de disolución va a encontrar formaciones pedogenéticas (terra rosa) donde poder enraizar y, en segundo lugar, porque es en ellas donde mejor se conserva la humedad. De esta manera, las plantas, en su crecimiento, van desarrollando raíces que actúan a modo de cuñas contribuyendo a disgregar las rocas, siguiendo los planos de las diaclasas y a preparar a éstas para el transporte.

Por otro lado, sin embargo, existen otra serie de formaciones vegetales que han dado lugar a una fosilización de parte de los canchales y a un mantenimiento de pequeños sectores de la cornisa, destacando entre ellas la hiedra Hedera helix, especie típica de los bosques centroeuropeos húmedos. En los canchales se ha encontrado en las partes marginales de los mismos, sobre todo donde existen acumulaciones de materiales gruesos, donde los troncos de la hiedra se desarrollan entre [133] las piedras formando una tupida red que juega un extraordinario papel estabilizador del material detrítico suelto.

Igualmente es notoria la existencia de especies relictas, testigo de la presencia en otras épocas de una cubierta vegetal adaptada a unas condiciones climáticas distintas de las actuales,

${ }^{12}$ ROSSELLÓ VERGER, V.M.: «Los canchales de montaña calcárea y los fenómenos termoclásticos» en Actas de la II Reunión Nacional del Grupo Español de Trabajo del Cuaternario. Jaca, 15-20 de Septiembre, 1975 p. 226.

${ }^{13}$ VARIOS: Guía ecológica de Baleares (colec. Guías Verdes de Incafo) edit. Caja de Ahorros y Monte de Piedad de Baleares. Madrid, 1978 p. 78. 
así por ejemplo, se ha encontrado hacia los $700 \mathrm{~m}$ de altitud y en la parte central de uno de los canchales estudiados, un tejo Taxus baccata y al pie mismo de la cornisa otros dos ejemplares, mientras que en otras áreas de la provincia de Alicante con una mayor humedad edáfica, se siguen conservando en agrupaciones más o menos importantes como en la sierra de Mariola o en el Carrascal de Alcoy ${ }^{14}$. Cabe entonces plantearse la cuestión de en qué medida es la deforestación un factor importante en la posible actuación presente de los canchales, puesto que «la destrucción de la cubierta vegetal permite que el agua ponga en movimiento por lavado los materiales finos» al tiempo que «al quedar las piedras libres de las raíces y la matriz se convierten en un medio muy móvil y se constituye la pedriza» ${ }^{15}$.

La acción del hielo.- Cuando se inició este trabajo se planteó, como una de las primeras premisas a desarrollar, el papel que había jugado el hielo en otros períodos más fríos y, sobre todo, el tratar de demostrar que todavía, en la actualidad, el hielo es el responsable de la formación de gran número de canchales de gravedad que cubren la vertiente septentrional en la Sierra de Bernia desde los 630 a los $870 \mathrm{~m}$. Sin embargo, esta última afirmación no es del todo cierta puesto que si bien el efecto de la helada juega un papel importante en el modelado, otras acciones como la kárstica o la acción biológica están ayudando a disgregar la cornisa de Bernia.

El examen de los datos climáticos nos muestra que durante unos cuantos días al año (entre 15 y 20) de Noviembre a Abril, se producen en dicha crestería temperaturas por bajo de $0^{\circ} \mathrm{C}$ y que durante el día éstas pueden tornarse en positivas por lo que los fenómenos de hielo-deshielo son frecuentes e importantes siempre que hayan sido precedidos de algún tipo de precipitación que haya permitido que la roca se empapase de agua. Por ello, se puede afirmar que los fenómenos de gelifracción están presentes en la cornisa de Bernia, lo cual se evidencia cuando se recorre detenidamente el terreno puesto que, inmediatamente, se reconocen [134] grandes bloques de rocas muy diaclasadas y al pie de ellas abundancia de material gelifracto.

La gelifracción.- Las calizas biohérmicas de grano medio a grueso y disyunción regular que están netamente estratificadas en bancos de 50 a $80 \mathrm{~cm}$ se vieron diaclasadas a través de líneas de debilidad estructural en los contactos litológicos de diferente resistencia durante el Mioceno inferior y medio en las fases de compresión y de distensión que originaron gran número de diaclasas, por donde el hielo, entre otros agentes, ejerce una acción muy activa.

En función de la relación que hay entre el espaciamiento de las líneas de debilidad estructural y la profundidad que alcance el hielo, se producirá macrogelifracción o microgelifracción. En el primer caso, se observan cantos entre 5 y $50 \mathrm{~cm}$ de eje mayor y es a quien se debe la alimentación de la mayor parte de los taludes de derrubios que tapizan la umbría de la cornisa de Bernia aunque el tamaño medio predominente es de 5 a $15 \mathrm{~cm}$.

A pesar de lo afirmado hay que hacer notar que, posiblemente, los canchales más orientales tengan un origen diferente de los occidentales, puesto que en la zona más oriental se han encontrado algunos ejemplares de palmito $(810 \mathrm{~m})$. Por ello, hay que admitir que en función de la gradación altitudinal de esta especie, el origen de los canchales de uno y otro sector sea distinto. Así, en el sector occidental, el palmito queda detenido a los $600 \mathrm{~m}$ de altitud en función de unas condiciones de mayor umbría cuyo efecto se deja sentir con mayor intensidad durante el invierno en que sin necesidad de que se produzca la precipitación, hay posibilidades de un mayor contenido de humedad en las rocas por la presencia de nubes que chocan contra la crestería superior de Bernia; de esta forma, cuando se ponen en contacto con la vegetación las diminutas gotas que flotan en el aire se depositan sobre hojas y ramas, cayendo, posteriormente,

${ }^{14}$ RIGUAL MAGALlÓN, A.: Flora y vegetación de la provincia de Alicante I.D.E.A. Alicante, 1972 p. 238.

15 BERNABÉ MAESTRE, J.M.: «Vegetación y morfología en las pedrizas de la montaña media» en Actas de la II Reunión Nacional del Grupo Español de Trabajo del Cuaternario. Jaca, 15-20 de Septiembre, 1975 p. 38. 
al suelo, de manera que al producirse un enfriamiento nocturno importante se crea una fina película de hielo en el suelo cuya acción morfogenética contribuye a disgregar la roca, mientras que en el sector oriental, la mejor exposición a los rayos solares limita las heladas y favorece la progresión altitudinal de esta especie. En consecuencia, en la parte oriental, los canchales tienen su origen en la acción biológica más que en el efecto de la gelifracción al que no hay que descartar del todo.

La gelifracción se presenta de forma predominante en la crestería que culmina la Sierra de Bernia. Dicha cornisa posee una potencia que oscila entre los 250 y los $300 \mathrm{~m}$ con una disposición prácticamente vertical de los estratos, estructurados en losas compactas, profusamente [135] diaclasadas donde el efecto de cuña del hielo ejerce una importante labor erosiva.

Las formas de deslizamiento.- Todo el material detrítico que se origina en la cornisa de Bernia, en el sector de la umbría, por cualquiera de los mecanismos morfoclimáticos descritos, gelifracción, biológico, karst, etc., está contribuyendo a la formación de un gran talud de derrubios que recubre toda esta ladera septentrional desde los $630 \mathrm{~m}$ hasta los $870 \mathrm{~m}$, en donde se inicia la cornisa.

En este talud, se han de distinguir dos partes: la inferior formada desde que la crestería de Bernia y toda la zona entró en una fase de tranquilidad orogénica, desde finales del Plioceno hasta el último período frío; y la superior, de recubrimiento, cuya formación se puede decir que es subactual o actual.

La parte inferior está constituida, claramente, por materiales que tienen su origen en coladas gelifluidales ligadas a condiciones climáticas de mayor crudeza por lo que se refiere al frío. El desarrollo de estas coladas es muy grande, ya que debieron descender al amparo de pendientes de $35^{\circ}$ a $40^{\circ}$.

Estas coladas gelifluidales, en la actualidad, están fosilizadas y recubiertas en parte por los canchales actuales. Pero su fosilización no sólo está justificada por la falta de condiciones climáticas apropiadas para su deslizamiento sino también por el hecho de que en algunas zonas, los materiales detríticos más recientes han llegado a constituir brechas cuando se origina una pérdida de agua procedente de la cornisa y se da una concentración por efecto de una helada superficial que produce la formación de calcita que puede cementar los cantos, como sucede en algunas áreas en las que estas brechas conglomeráticas recubren un sector de lóbulo, como en la parte inferior del canchal de los Pinos y del Barranco.

El perfil longitudinal de algunas de estas coladas gelifluidales nos muestra claramente un escalonamiento de lóbulos solifluidales que en algunos casos presenta 3 ó 4 escalones y cuyos peldaños se alargan más cuanto mayor es el descenso altitudinal, aunque los últimos es imposible saber sus dimensiones o sin tan siquiera existieron otros escalones, ya que todo el conjunto está siendo atacado por la erosión remontante que desde el Barranco del Estret y por el paraje de Pinos está procediendo a su vaciado.

Estos depósitos periglaciares superficialmente se parecen a acumulaciones de material detrítico con formas caóticas y que se localizan en toda la vertiente septentrional de la Sierra de Bernia, con pendientes de 35 a $40^{\circ}$. El material superficial es grosero y, con frecuencia, engloba algún bloque, mientras que por debajo se encuentran depósitos caóticos [136] de materiales detríticos con matriz intersticial y que constituyen coladas gelifluidales relictas. El estudio de las mismas se ha realizado con la obtención de muestras que, posteriormente, han sido tratadas en el laboratorio. Superficialmente, han sido fuertemente trastocadas, puesto que se han constituido unas tierras que permitieron su cultivo en otras épocas hasta cotas de 700 y $800 \mathrm{~m}$ de altitud.

Las muestras han sido obtenidas en dos localizaciones diferentes y pertenecen a dos coladas gelifluidales situadas en el canchal de la Cantera y en el del Barranco. La primera de 
ellas (muestra $n^{\circ} 3$ ) pertenece a una cata realizada en la parte lateral del lóbulo de solifluxión en su sector terminal donde, gracias a la existencia de una cantera en explotación actual, han podido ser recogidos los materiales. Se trata de un depósito de espesor considerable (4 ó $5 \mathrm{~m}$ ) en el que los análisis de laboratorio han puesto de manifiesto un predominio de la fracción gruesa $(52,5 \%)$ pero con cantos que no superan nunca los $7 \mathrm{~cm}$ en su eje mayor, siendo los más abundantes los comprendidos entre 2 y $3 \mathrm{~cm}$. La naturaleza de los cantos es, claramente, calcárea, presentando un grado de desgaste en sus aristas con un claro predominio del sector subangular $(58,4 \%)$ y envueltos en una matriz de textura limo-arenosa, color M7.5YR 6/6.

Las muestras $8 \mathrm{a}$ y $8 \mathrm{~b}$ han sido extraídas de la colada gelifluidal sobre la que se ha depositado el canchal del Barranco. La $8 \mathrm{a}(440 \mathrm{~m})$ ha sido tomada de la parte lateral del lóbulo recubierto en este sector por cantos de talla crioclástica pertenecientes al canchal. E1 57,8\% de la muestra está constituida por material grueso a base de cantos de caliza (entre 2 y $10 \mathrm{~cm}$ ) rubefactados y con aristas ligeramente desgastadas (62,1 subangulares). En esta capa aparecen, igualmente, porciones de brecha calcárea conglomerática cuyo cemento lo constituye la arcilla de descalcificación, probablemente por contracción de la misma en el proceso de desecación, si bien en ocasiones esta arcilla se presenta en nódulos aislados englobando pequeños cristales de calcita. Tanto los cantos como las concreciones se hallan envueltos en una matriz arcillo-arenosa que constituye el 29,8\% del total del material extraído y cuyo color corresponde a M5YR 3/4.

La muestra $8 \mathrm{~b}(414 \mathrm{~m})$ se localiza en la parte frontal del lóbulo de solifluxión en su sector terminal, sin recubrimiento de crioclastos. La fracción más abundante es la fina $(67,8 \%)$ con una textura arcillo-arenosa color M5YR 4/6 que engloba cantos de componente calizo-margosa con un grado de desgaste de mayor rodamiento que las muestras anteriores, ello se debe, fundamentalmente, a su situación en la parte terminal inferior del lóbulo de solifluxión. Igualmente, dentro de la fracción gruesa, existe una gran abundancia de concreciones de terra rosa y de [137] nódulos de cal que suponen el 45,4\% del total de dicha fracción.

Por encima de estas coladas gelifluidales y recubriéndolas en extensas zonas, pero localizados en la parte más próxima a la cornisa, se encuentran los canchales de derrubios actuales que pueden alcanzar longitudes de hasta 75 ó $100 \mathrm{~m}$. Estos canchales están constituidos por el material calcáreo que por gelifracción, karstificación o acción biológica está siendo arrancado de la cornisa de Bernia en su parte septentrional, por lo que va a presentar una estructura muy heterométrica, aunque aquí predomina el material grueso con unas dimensiones en los ejes mayores de los cantos que oscilan entre los 5 y $20 \mathrm{~cm}$ entre los que se entremezclan algunos de hasta $60 \mathrm{~cm}$ y $\sin$ que exista apenas matriz arcillosa, salvo en su base, donde se produce una pequeña acumulación o en el contacto con la colada gelifluidal que lo que soporta. El espesor de estos canchales es muy débil, sólo se trata de capas superficiales de cantos en las partes altas de unos 20 ó $30 \mathrm{~cm}$, que pueden alcanzar hasta 1 ó $2 \mathrm{~m}$ en las inferiores.

Otro hecho a destacar es la aparición en los canchales de la crestería $\mathrm{N}$ de la Sierra de Bernia de escalones paralelos a las curvas de nivel y separados entre sí, aproximadamente, unos 1, 5-2,0 m. Este fenómeno hay que relacionarlo con dos elementos básicos: en primer lugar, con la existencia de un sustrato de masa gelifluidal y, en segundo lugar, con unas condiciones térmicas y de humedad determinadas. Este es un elemento muy importante de cara a dilucidar el problema del funcionamiento actual o relicto de estas formas periglaciares si tenemos en cuenta que este área sufre una importante actividad antrópica de aprovechamiento ganadero de la que ya CAVANILLES en el s. XVIII dejó constancia en su obra al hablar del fuerte situado en la ladera meridional de la sierra «allí encierran los pastores sus ganados y tienen la comodidad de una fuente que aún en verano suele dar caño de tres pulgadas» ${ }^{16}$ que habría hecho desaparecer

${ }^{16}$ CAVANILLES, A. J.: Observaciones sobre la historia natural, geografía, agricultura, población y frutos del Reyno de Valencia. Imprenta Real, Madrid, $17972^{\text {a }}$ edic., Valencia, 1981 p. 234. 
tales formas.

Hasta aquí, se ha realizado una descripción de las acumulaciones de ladera basada en las observaciones realizadas sobre el terreno donde se llevaron a cabo análisis dinámicos de los cantos siguiendo el diagrama de POSER y HÖVERMANN ${ }^{17}$ para lo cual se estudiaron 6 masas de depósitos con un total de 10 muestras que dieron los siguientes resultados: [138]

\begin{tabular}{|c|c|c|c|c|c|c|}
\hline \multirow{2}{*}{$\begin{array}{l}\text { Núm. } \\
\text { Muestra }\end{array}$} & \multirow{2}{*}{$\begin{array}{l}\text { Altitud } \\
(m)\end{array}$} & \multicolumn{3}{|c|}{ Diagrama de Poser } & \multirow[b]{2}{*}{$\underline{I V}$} & \multirow[b]{2}{*}{$\underline{\text { Tipo de Derrubios }}$} \\
\hline & & $\underline{I}$ & $\underline{I I}$ & $\underline{I I I}$ & & \\
\hline \multirow[t]{2}{*}{$1 \mathrm{a}$} & 820 & 50 & 24 & 14 & 12 & Canchal sobre \\
\hline & & & & & & masa solifluidal \\
\hline \multirow[t]{2}{*}{$1 b$} & 870 & 58 & 17 & 19 & 6 & Canchal sobre \\
\hline & & & & & & masa solifluidal \\
\hline \multirow[t]{2}{*}{$2 \mathrm{a}$} & 860 & 38 & 22 & 24 & 16 & Canchal sobre \\
\hline & & & & & & masa solifluidal \\
\hline \multirow[t]{2}{*}{$2 b$} & 840 & 51 & 24 & 14 & 11 & Canchal sobre \\
\hline & & & & & & masa solifluidal \\
\hline \multirow[t]{2}{*}{3} & 715 & 51 & 15 & 15 & 19 & Masa de ripio \\
\hline & & & & & & solifluidal \\
\hline \multirow[t]{2}{*}{$4 a$} & 750 & 27 & 50 & 14 & 9 & Canchal sobre \\
\hline & & & & & & masa solifluidal \\
\hline \multirow[t]{2}{*}{$4 b$} & 790 & 27 & 45 & 24 & 4 & Canchal sobre \\
\hline & & & & & & masa solifluidal \\
\hline \multirow[t]{2}{*}{5} & 810 & 35 & 36 & 19 & 10 & Canchal sobre \\
\hline & & & & & & masa solifluidal \\
\hline \multirow[t]{2}{*}{$6 a$} & 751 & 40 & 22 & 24 & 14 & Canchal sobre \\
\hline & & & & & & masa solifluidal \\
\hline $6 b$ & 758 & 46 & 19 & 23 & 12 & Canchal sobre \\
\hline
\end{tabular}

Como se desprende de estos datos hay una clara distinción entre masa de ripio solifluidal y canchal sobre masa de ripio solifluidal. En el primer caso, se trata de las coladas cuya descripción se efectuó anteriormente y que nos aparecieron como formaciones relictas.

17 POSER, H. und HÖVERMANN, J.: «Untersuchungen zur pleistozäner Harz Vergletscherung» $A b h$. Braunschweig-Wiss Ges., III pp. 61-155. 
Sin embargo, los canchales sobre masa solifluidal, se vio claramente que seguían funcionando y que constituyen una forma de deslizamiento muy activa en la zona por las siguientes razones:

1) Prácticamente aparecen todos ellos desprovistos de vegetación y si ésta existe, se encuentra en una continua lucha contra el deslizamiento de toda la masa de cantos gelifractos, sobresaliendo la Hedera helix, especie que se presenta en manchas de longitud variable con débil cobertura pero que, en ocasiones, constituye una red bastante tupida que puede producir la retención temporal del talud de derrubios. Esta labor de fijación y retención puede desaparecer cuando se produce un brusco descenso del mismo, de ahí que, a veces, se encuentre entre los cantos restos de hiedra fraccionados.

2) En las partes altas de los canchales de ripio sobre masa solifluidal aparecen senderos, escalones perpendiculares a la pendiente que están separados por término medio unos $2 \mathrm{~m}$. En realidad este hecho es uno [139] de los más interesantes, puesto que su deslizamiento implica la necesidad de la actuación del hielo en el substrato que lo soporta. Deben ser fruto de la humedad y de los procesos mecánicos del hielo-deshielo, así como de la influencia que directamente ejercen las nevadas que sobre estas zonas suelen tener alguna importancia, todo ello a favor de fuertes pendientes que se aproximan a $\operatorname{los} 45^{\circ}$ ó $50^{\circ}$. Este agua se almacena en el substrato y en las calizas de la cornisa que poco a poco será evacuada sobre estas áreas que, además, son las más expuestas a los enfriamientos que se producen en los meses invernales durante la noche. En consecuencia, el mecanismo hielo-deshielo contribuye a que se vayan produciendo pequeños desplazamientos superficiales de hasta un par de metros que son los que, en definitiva, van a ir configurando ese escalonamiento al que antes se aludía.

3) Los canchales sobre masa solifluidal son formas vivas, muy activas, puesto que en muy poco tiempo han vuelto a ocupar los espacios que la acción antrópica les había ganado para el cultivo de viñedos. Así, muchas de las tierras abandonadas en los últimos quince años han vuelto a ser ocupadas por estas formas de deslizamiento. Además, la agricultura que se practicó en estas áreas tuvo que mantener una lucha constante contra las mismas, como lo atestigua el gran número de muretes construidos por el hombre con los cantos de mayores proporciones y que, todavía hoy, se pueden contemplar en algunas zonas de este piedemonte.

Acción antrópica.- Entre los factores que coinciden en el proceso de evolución de vertientes y que restan solidez al posible protagonismo hoy del fenómeno periglacial, se encuentra la acción antrópica. Ésta se viene manifestando, como nos muestra CAVANILLES en su obra, desde hace algunos siglos «...la larga cuesta de dos horas por las faldas de Bernia se ve plantada de viñas en las alturas, seguida hacia baxo de sembrados, higueras, almendros y

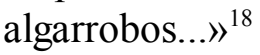

Esta explotación agrícola que llama la atención al historiador no deja de asombrarnos hoy, al encontrarnos abancalamientos hasta la altura de los $640 \mathrm{~m}$, con cultivos de almendros y olivos, incluso la presencia de huertas hasta los $500 \mathrm{~m}$ de altitud. Teniendo en cuenta que la base de los canchales se encuentra en algunos de ellos a los $650 \mathrm{~m}$ se comprende que la interferencia de la acción antrópica sea considerable. Además es de destacar que estos aterrazamientos se han desarrollado en los tramos superiores sobre el lóbulo de solifluxión que recubren los canchales, comprobando en los bancales la rubefacción de la matriz arcillosa y los cantos gelifractos que ésta engloba. [140]

El Prof. ROSSELLÓ VERGER destaca esta acción antrópica, igualmente, en una descripción de este sector que realiza en la Geografía de la Provincia de Alicante: «el ejemplo más patente de clasificación lo ha hecho el hombre en la falda de Bernia al acondicionar los canchales en estrechas terrazas para viñedo que al lado justo crece entre el mismo ripio

\footnotetext{
${ }^{18}$ CAVANILLES, A. J.: Op. cit. p. 234.
} 
crioclástico» ${ }^{19}$.

El laboreo de estas cotas algo elevadas, por parte de la población de Benisa y Jalón, es pues un hecho que se viene manifestando desde largo tiempo y que hoy no ha cesado aún, ya que los lugareños, de tradición eminentemente agrícola, mantienen sus viviendas en la Sierra Bernia, que ocupan los fines de semana y durante los meses estivales, al cobijo de la umbría que les depara la sierra.

A esta acción antrópica hay que añadir la pervivencia de una práctica muy extendida en todo el sector, la caza, que reúne a un gran número de aficionados que en época de licencia realizan batidas frecuentes por toda la sierra, ayudando con ello a provocar deslizamientos en las vertientes inconexos al modelado periglacial.

Añadiremos, también, la existencia, como se dijo anteriormente, de ganado trashumante desde tiempo secular ${ }^{20}$ y que hoy se mantiene procedente del municipio de Jalón. Esta ganadería queda estabulada en la sierra durante algún tiempo en base a la presencia aquí de pastos y aguas. Asombrosamente, el ganado asciende hasta la cornisa de la sierra donde en el contacto con el talud aparecen, en ocasiones, concavidades de origen kárstico que ofrecen un resguardo al ganado. La acción de este ganado trashumante como factor erosivo no debe despreciarse a la hora de valorar los fenómenos del modelado periglacial y su funcionalidad actual.

Igualmente, un hecho a destacar y que se relaciona con la vegetación de la Sierra de Bernia es que ha sufrido un continuo proceso de deforestación, motivado, en un primer momento, por su afán de roturación como consecuencia de la explosión demográfica del s. XIX y que, posteriormente, ha sido abandonada por la escasa productividad de dichos terrenos al ser en extremo dificultosas las labores de mecanización; restos de estas roturaciones se encuentran en cotas próximas a los $700 \mathrm{~m}$, si bien por debajo de esta altitud todavía subsisten parcelas labradas aunque bajo un régimen de explotación familiar, sin tendencia a la comercialización. Así, en relación con este proceso de deforestación, en el [141] s. XVI, VESPASIANO GONZAGA $^{21}$ afirmaba que la Sierra de Bernia estaba toda ella cubierta de romeros, lentiscos y pinos, estos últimos hoy, prácticamente, han desaparecido en las partes altas, si bien ICONA está llevando a cabo tareas de repoblación de dicha especie en el área.

\section{Conclusiones}

Cuando se inició el estudio, se puso como premisa fundamental el dilucidar el papel que jugaba el periglaciarismo en la umbría de la Sierra de Bernia, en base a la presencia de unas formas de acumulación que cubrían extensas zonas con espesores considerables.

La primera aproximación a su análisis nos indicó que este primer planteamiento era válido solamente en parte, ya que el periglaciarismo dejó profundas huellas durante épocas cuaternarias pasadas pero, en la actualidad, su acción era muy reducida y limitada a una estrecha franja comprendida entre los $800 \mathrm{~m}$ y la culminación de la sierra a los $1.120 \mathrm{~m}$ con unas acciones muy superficiales.

Por el contrario, otras actuaciones morfológicas fueron detectadas como protagonistas fundamentales del modelado que hoy ofrece dicha vertiente.

19 ROSSELlÓ VERGER, V. M. y BERNABÉ MAESTRE, J. M.: «La montaña y sus valles...» Op. cit. p. 104.

${ }^{20}$ CAVANILLES, A. J.: Op. cit. p. 234.

${ }^{21}$ A.G.S., Memorial de lo que cumple Su Mgd. mande proveher para la fortificación del Reyno de Valencia. Sección de Estado, legajo 141, fols. 171 y ss. años 1562, citado en QUEREDA SALA, J. J.: Comarca de la Marina (Alicante). Estudio de Geografia Regional. Excma. Dip. Prov. de Alicante. Alicante, 1978 p. 93. 
Destacamos como efectos erosivos básicos los fenómenos de karstificación, íntimamente ligados a las condiciones litológicas que, a su vez, en las cornisas de fuerte pendiente, favorecen la actuación de mecanismos de gelifracción. La acción de las plantas en la cornisa de Bernia se muestra, también, como un agente del modelado de gran poder erosivo, que llega a producir el estallido de las rocas a favor de las diaclasas, hecho que provoca la aparición de zonas de canchales que cubren extensas áreas.

Finalmente, hay que señalar una acción antrópica muy intensa que tiende a desfigurar la morfología periglacial relicta y las formas que se están construyendo en la actualidad.

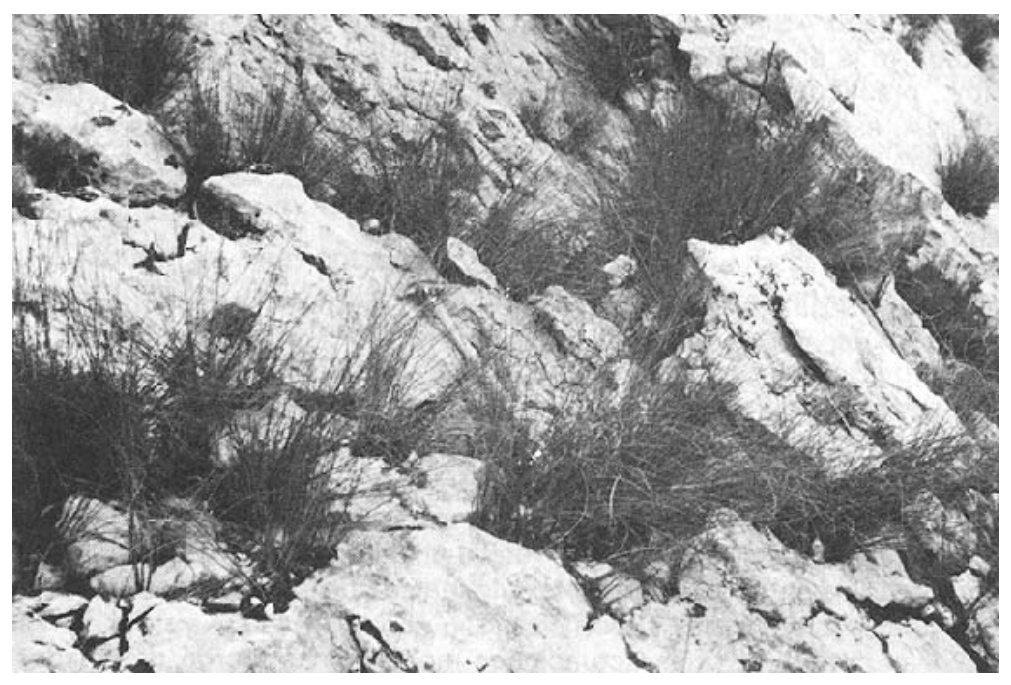

Stipa juncea instalada en las diaclasas de la cornisa de Bernia.

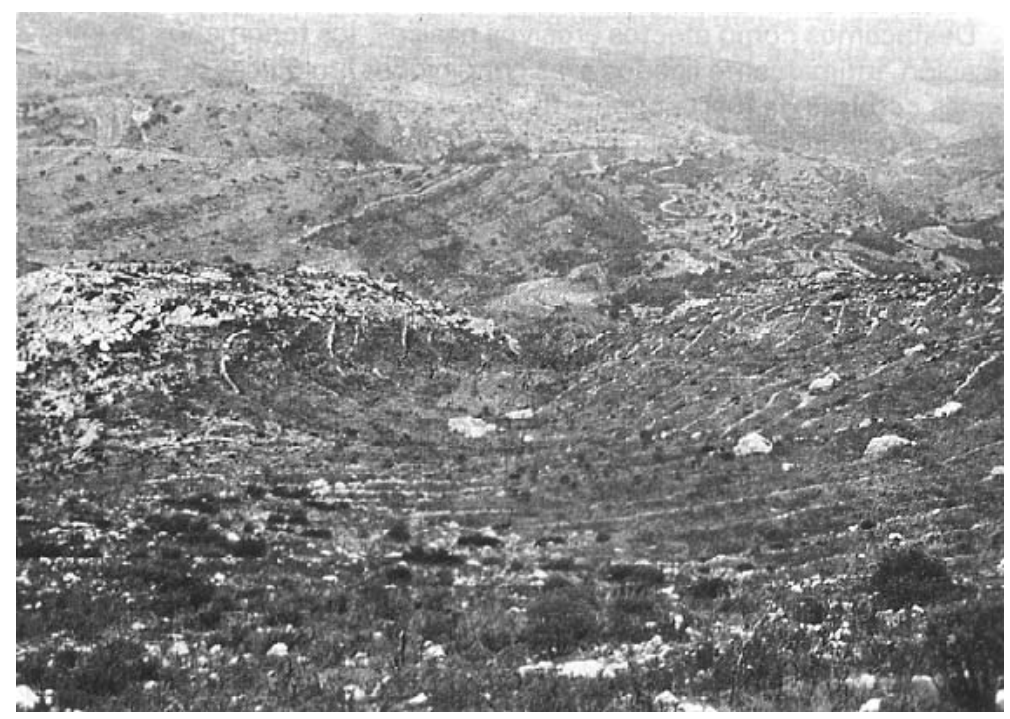

Dolina ubicada al pie de la cornisa de Bernia. Obsérvese el antiguo abancalamiento siguiendo las curvas de nivel. 


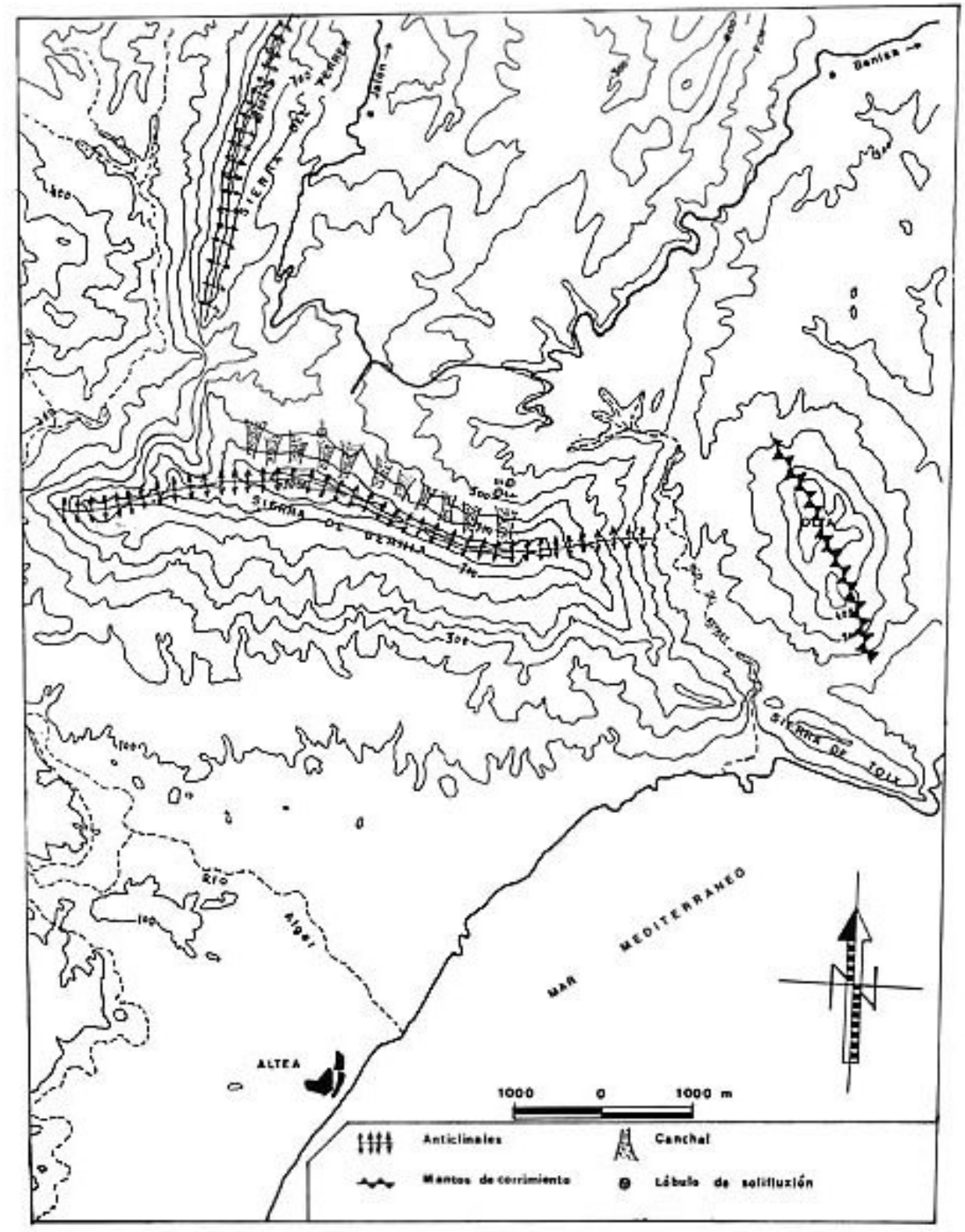

VIII 


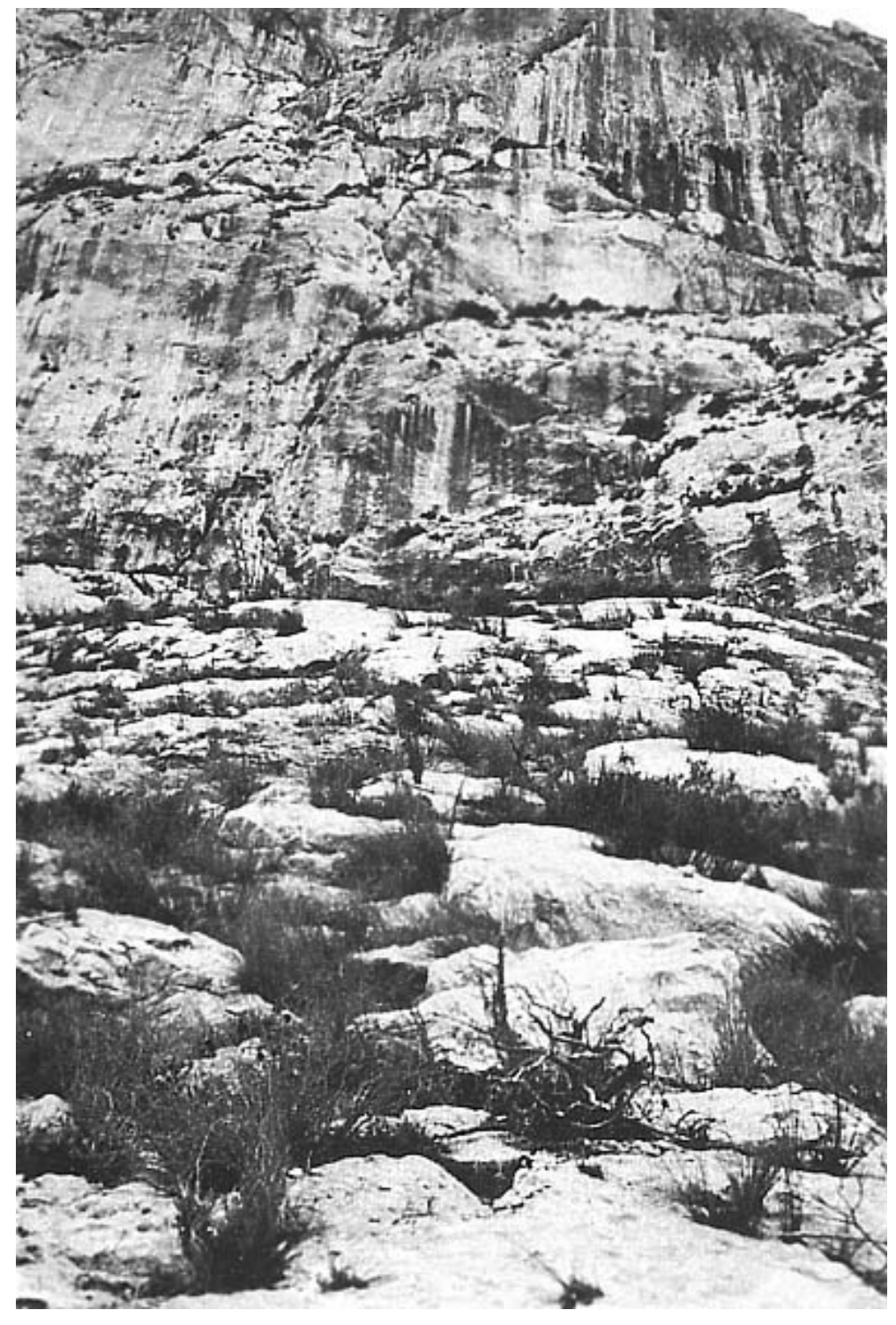

Crestería culminante de Bernia. 


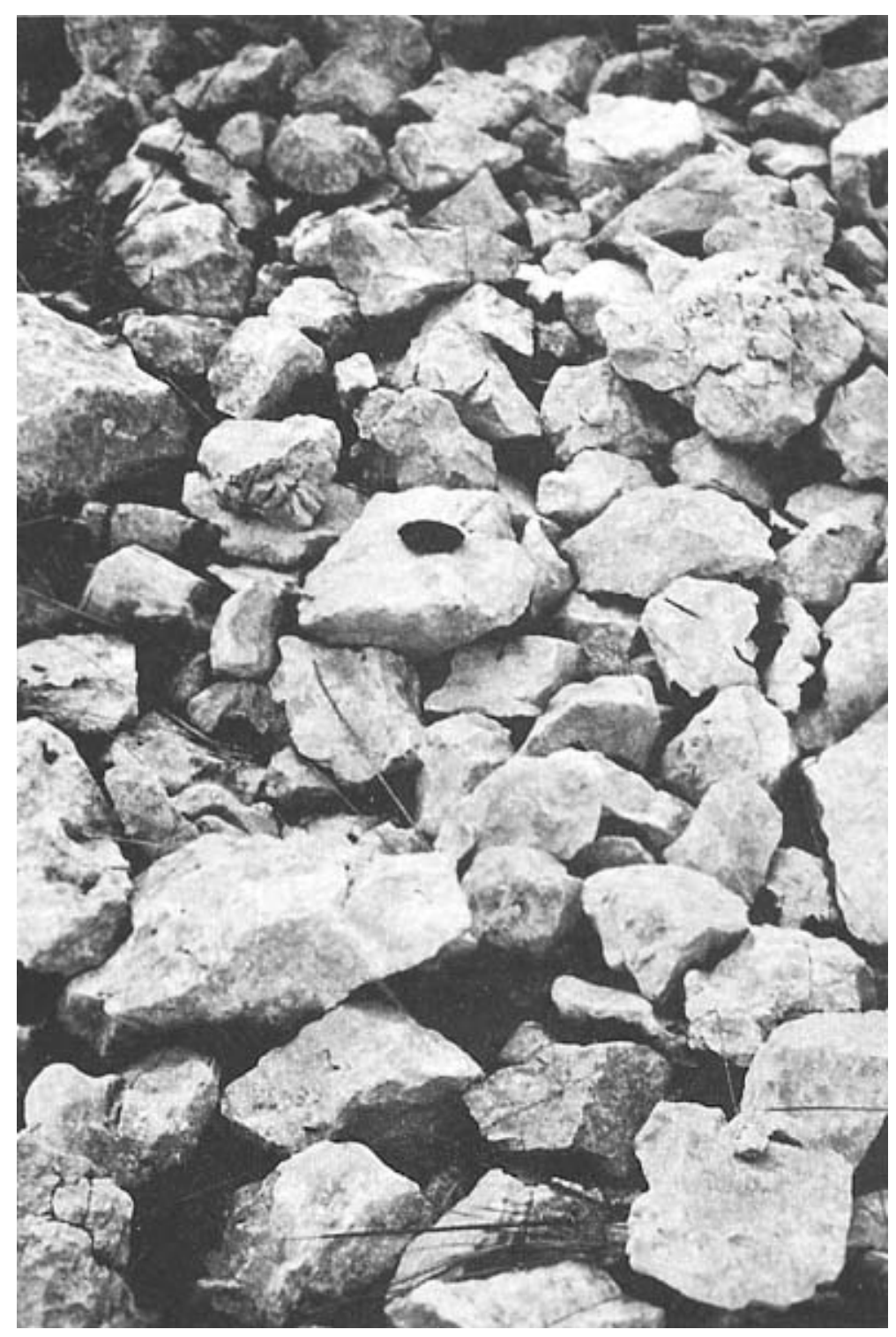

Material gelifracto al pie de la cornisa. 


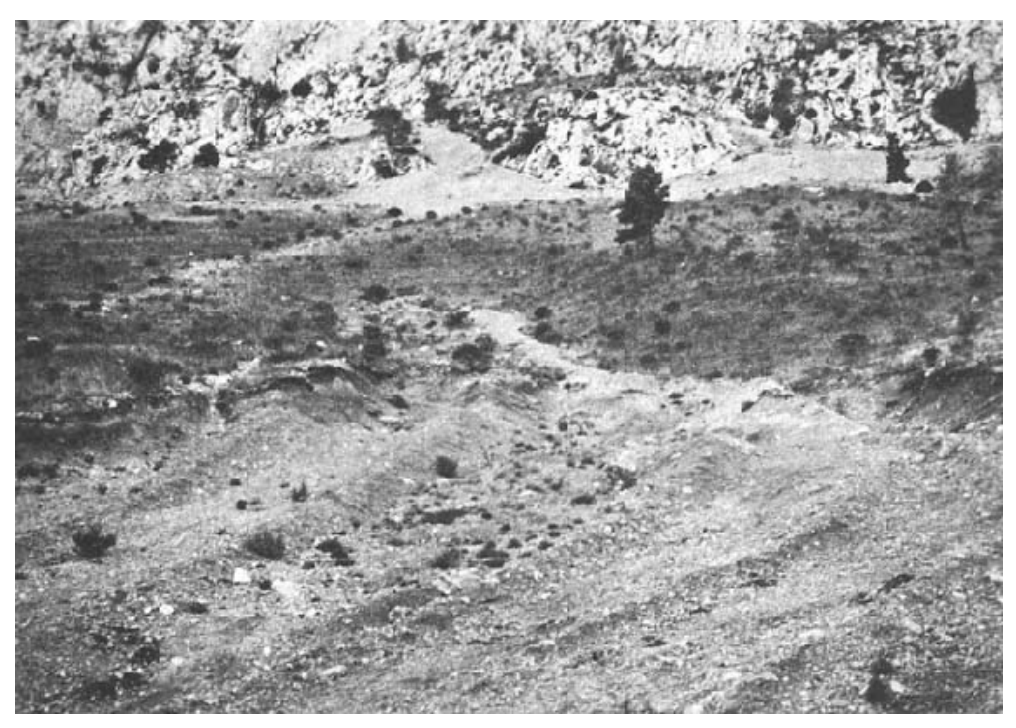

Lóbulo de solifluxión recubierto en la parte superior por canchales. En la parte derecha de los mismos aparece un tejo.

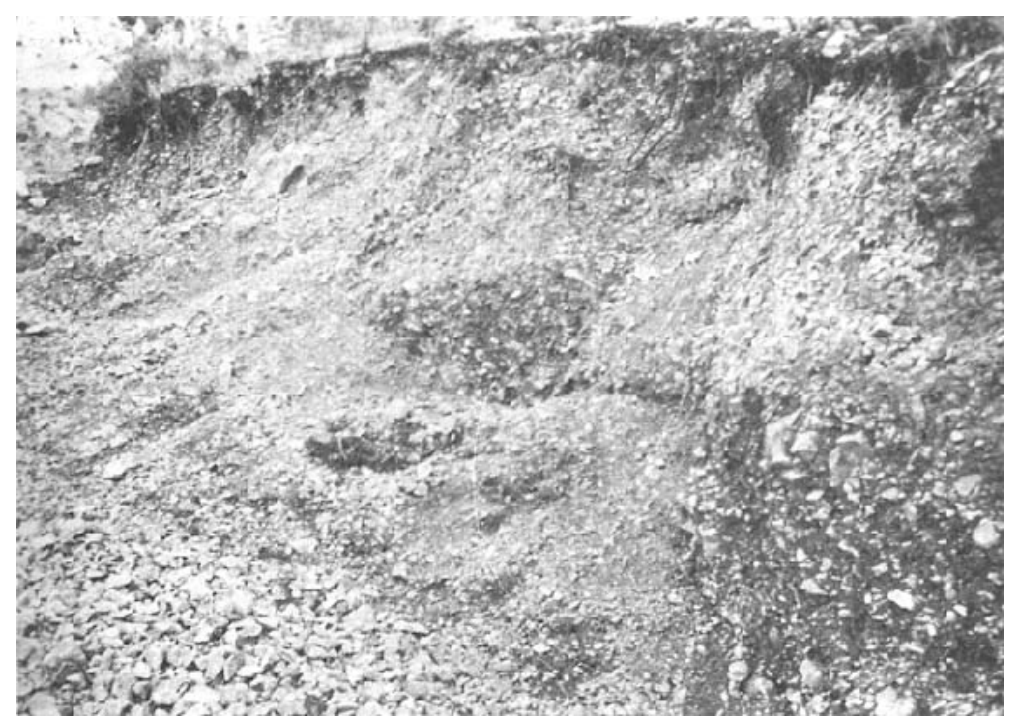

Detalle del lóbulo de solifluxión. 